\title{
Crianças anencefálicas e doações de órgãos: questões legais e éticas no Brasil
}

\section{Anencephalic children and organ donation: ethical and legal issues in Brazil}

\author{
Fabiana Iglesias de Carvalho', Carmen Silvia Molleis Galego Miziara²
}

Carvalho FI, Miziara CSMG. Crianças anencefálicas e doações de órgãos: questões legais e éticas no Brasil. Saúde, Ética \& Justiça. 2012;17(1):3-11.

RESUMO: O objetivo dessa monografia é avaliar o desafio médico, jurídico e ético conferido pela anencefalia ao debate sobre a utilização de órgãos provenientes de neonatos anencéfalos para fins de transplante sob o ponto de vista bioético no Brasil. Os métodos utilizados para a realização deste estudo foram o método descritivo e exploratório; e a técnica bibliográfica foi realizada a partir de livros, revistas, artigos científicos e periódicos. A anencefalia, um grave defeito embrionário do sistema nervoso central, tem sido alvo de incitados debates em diversos setores da sociedade brasileira surgindo destes, diversas questões: i) Recém-nascidos com anencefalia podem ser considerados como pessoas?; ii) eles são potenciais doadores de órgãos?; iii) em caso afirmativo, em que circunstâncias?; iv) a definição de morte ou de morte encefálica pode ser alterada?; v) se deve ser praticado o suporte intensivo de vida para recém-nascidos com anencefalia? Deve ser apoiada a prática intensiva para a manutenção da vida de recém-nascidos com anencefalia? vi. Como devem ser determinadas prioridades neonatais em unidades com recursos limitados? Com isso o presente trabalho tem como finalidade debater acerca do anencéfalo enquanto doador de órgãos, como também as questões legais e éticas que envolvem o tema.

DESCRITORES: Anencefalia; Doação dirigida de tecidos/ética; Doadores de tecidos/ética; Bioética; Medicina legal/ética.

1.Pós-graduanda do curso de Especialização em Medicina Legal - Departamento de Medicina Legal, Ética Médica, Medicina Social e do Trabalho - FMUSP.

2. Médica do Departamento de Medicina Legal, Ética Médica, Medicina Social e do Trabalho - FMUSP.

Endereço para correspondência: Fabiana Iglesias de Carvalho Lemos Torres. CEP 04023-062. São Paulo, SP.

E-mail: fabianaiglesias@ig.com.br 


\section{INTRODUÇÃO}

$\mathrm{H}$ á vários anos, a possibilidade de substituir órgãos doentes por outros sadios fascinou a humanidade. Depois de vários fracassos e de várias pesquisas, o transplante de órgãos e tecidos passou a ser aceito como método terapêutico legal, graças aos avanços das técnicas cirúrgicas e da introdução de fármacos imunomoduladores.

O acréscimo da realização de transplantes acarretou, além da cura de pacientes, contradições bioéticas e jurídicas em razão da inviolabilidade e inalienabilidade do corpo, as quais balizaram normas de condutas, capazes de equilibrar um caráter aceitável de rompimento da integridade do corpo humano com a possibilidade de remoção de estruturas para fins terapêuticos.

Assim, ao mesmo tempo em que se melhorou a saúde do paciente com a obrigação primária dos cuidados médicos, tais normas procuraram repudiar o comércio de órgãos e tecidos, a transgressão da autonomia de doadores e receptores e a utilização rotineira de estruturas provenientes de seres humanos em situação de fragilidade (prisioneiros, deficientes físicos, desvalidos, crianças seqüestradas) $)^{50,55}$

A anencefalia, um grave defeito embrionário do sistema nervoso central, tem sido alvo de acalorados debates em diversos setores da sociedade brasileira. $\mathrm{O}$ tema gera grande interesse ao envolver a questão do abortamento. Igualmente, os direitos femininos são também trazidos à tona, em face da possibilidade de se conceder à mulher a decisão de continuar ou não a gestar feto anencéfalo ${ }^{37}$.

Sendo a morte um processo de eventos sucessivos, o exato momento de sua instalação é de precisão difícil, se não impossível. Para tanto, a Resolução CFM nำ 1.480 exige a realização de exames clínicos e complementares durante intervalos de tempo variáveis, próprios para determinadas faixas etárias, ensejando a constatação da falência inequívoca e irreversível, motivada por causa conhecida, da vida de relação, sediada no córtex cerebral, e também da vida vegetativa, coordenada por centros nervosos localizados no tronco encefálico.

Os critérios clínico-laboratoriais de morte encefálica estabelecidos pela Resolução CFM no 1.480 são válidos para indivíduos de qualquer idade, exceto para as crianças menores de sete dias e prematuros ${ }^{47}$.

Diversas perguntas podem ser levantadas: Recém-nascidos com anencefalia podem ser considerados como pessoas? Eles são potenciais doadores de órgãos? Em caso afirmativo, em que circunstâncias? A definição de morte ou de morte encefálica pode ser alterada? Deve-se apoiar o suporte de vida intensivo para recém-nascidos com anencefalia em antecipação de morte encefálica? Como devem ser determinadas as prioridades neonatais em unidades com recursos limitados?

No campo da bioética, verificam-se posicionamentos divergentes quanto ao tema, que se evidenciam ao se observar a postura ética adotada na Resolução no 1.752/04 do Conselho Federal de Medicina (CFM).

\section{OBJETIVOS}

\section{OBJETIVO GERAL}

O objetivo geral deste trabalho é analisar o desafio médico, jurídico e ético imposto pela anencefalia ao debate sobre a utilização de órgãos oriundos de neonatos anencéfalos para fins de transplante sob o ponto de vista bioético no Brasil.

\section{OBJETIVOS ESPECÍFICOS}

Apresentar o conceito e características da anencefalia;

- Conhecer parâmetros bioéticos acerca do tema anencefalia e analisar a relação entre a anencefalia e o transplante de órgãos;

- Apresentar as questões legais do anencéfalo como doador de órgãos.

\section{MÉTODO}

A técnica de pesquisa foi a bibliográfica, realizada a partir de livros, revistas, artigos científicos, periódicos.

Para o alcance dos objetivos propostos, será realizado estudo retrospectivo do tipo descritivoexploratório com abordagem qualitativa na base de dados médicos (PubMed), utilizando os descritores "Organ Donation" "e "Anencephaly" com limites para língua inglesa e publicações após 2003, de acordo com as palavras-chave reconhecidas no Medical Subjects Headings (MESH). Encontramos 16 artigos, dentre estes, foram analisados oito artigos, publicados em língua portuguesa ou inglesa.

\section{RESULTADOS}

\section{Anencefalia}

Na revisão da literatura, traremos inicialmente 
a conceituação e as características da Anencefalia, a discussão sobre o transplante de órgãos e os aspectos bioéticos sobre o tema.

\section{Conceituação e CARActerísticas}

A origem da anencefalia vem do grego, onde "An" significa sem e "Enkephalos" significa encéfalo (Vargas, 2004).

Anencefalia significa ausência de encéfalo; o termo, contudo, é impróprio, visto que a malformação consiste na associação de acrania com desenvolvimento rudimentar de estruturas do prosencéfalo e do mesencéfalo. Portanto, definese com este termo uma malformação rara do tubo neural que ocorre entre o $16^{\circ}$ e o $26^{\circ}$ dia de gestação, na qual verifica-se ausência, completa ou parcial, da calota craniana e dos tecidos que a ela se sobrepõem e grau variado de malformação e destruição dos esboços do cérebro exposto. As estruturas derivadas do rombencéfalo, ou seja, o cerebelo, a ponte e o bulbo, costumam desenvolverse a ponto de possuírem centros nervosos bem estruturados e funcionais ${ }^{31}$.

Além das malformações citadas, podem existir outras malformações concomitantes de outras estruturas do corpo; as vísceras podem estar normais, a não ser pelas alterações específicas decorrentes da disfunção cerebral, ou apresentar quaisquer tipos de anomalias congênitas, desde os mais leves às que incapacitem a atuação fisiológica do órgão ${ }^{51}$.

O diagnóstico pré-natal é possível através do screening da alfa fetoproteína materna e da ultra-sonografia. Os dois métodos associados demonstraram uma sensibilidade entre 80 e 100\%. Segundo a Federação Brasileira das Associações de Ginecologia e Obstetrícia (www.febrasgo.org. br), a anencefalia é a malformação fetal mais freqüente. Estimativas apontam para a incidência de aproximadamente um em cada 1.600 nascidos vivos.

Se entre 40 e $60 \%$ dos anencéfalos nascem vivos, após o nascimento, apenas $8 \%$ sobrevivem mais de uma semana, $1 \%$ vive entre um e três meses. O Comitato Nazionale per la Bioetica relata ainda um caso de sobrevivência até 14 meses e outros dois entre 7 e 10 meses $^{19}$.

Quanto à viabilidade pós-natal, vale ressaltar que de um quarto a um terço dos anencéfalos dados à luz preenchem os critérios de nascido vivo ${ }^{34} \mathrm{e}$ que, após o nascimento com vida, os centros respiratório e vasomotor, localizados no tronco encefálico, garantem a ele sobrevida variável ${ }^{38}$.

A despeito de o anencéfalo ser capaz de respirar de maneira autônoma, de executar movimentos com a musculatura voluntária e de apresentar quase todos os reflexos primitivos dos neonatos, entre eles, o reflexo de sucção, existe quem afirme tratar-se de uma malformação incompatível com a vida extrauterina ${ }^{25}$. Há, ainda, quem entenda que as manifestações vitais do anencéfalo, pela brevidade de sua duração, não são suficientes para fazerem dele um ser vivo pleno ${ }^{54}$.

\section{Morte encefálica}

O conceito de morte encefálica foi proposto pela primeira vez em uma "Comunicação Especial" ao Journal of the American Medical Association, em 1968, por um Comitê da Harvard Medical School. Os outros critérios para a definição de morte encefálica foram desenvolvidos principalmente nos Estados Unidos, e, a partir de 1981, para crianças com cinco ou mais anos de idade ${ }^{45}$. Em 1987, foram incluídos os neonatos de termo com sete ou mais dias de vida ${ }^{52}$.

No ano de 1988, o Congresso Nacional Brasileiro emitiu parecer determinando que o Conselho Federal de Medicina (CFM) era o órgão capacitado e responsável para decisões relacionadas à área médica. Em 1991, o CFM reconheceu que a morte encefálica tem equivalência à morte clínica, de acordo com os conceitos vigentes em quase todo o mundo. Em 1993, através do Decreto $n^{\circ} 879$ sancionado pelo Presidente da Republica Itamar Franco, regulamentando a Lei $\mathrm{n}^{\circ}$ 8.489, de 18 de novembro de 1992, que dispõe sobre a retirada e transplante de tecidos, órgãos e partes do corpo humano, isto fica transparente no artigo 3-inciso V-: Morte Encefálica: a morte definida, como tal, pelo Conselho Federal de Medicina e atestada por médico. No ano de 1997, o CFM apresentou a Resolução n 1.480, adotando critérios diagnósticos de morte encefálica no Brasil para crianças a partir dos sete dias de vida.

Esta Resolução normatizou os critérios para morte encefálica no Brasil e adota parâmetros semelhantes aos americanos para morte encefálica. Contudo, não permite a utilização de provas de fluxo sanguíneo cerebral em todo o primeiro ano de vida, como comprobatório de morte encefálica; e exige sempre a realização de um exame subsidiário para a definição diagnóstica, independentemente da idade (Brasil, 1997).

De modo geral, o diagnóstico da morte encefálica é facilmente estabelecido ${ }^{27}$. Para esta avaliação, devem ser excluídas causas reversíveis de coma, como intoxicações, envenenamentos, distúrbios hidroeletrolíticos ou endocrinológicos ${ }^{27}$. 
Ademais, é necessário atentar durante o exame clínico para a temperatura corpórea. A presença de hipotermia (temperatura menor que $32,2^{\circ}$ Celsius) deve ser combatida além de ser indispensável à estabilização do quadro hemodinâmico, pois o choque, assim como a hipotermia, pode reduzir o metabolismo cerebral e determinar a abolição de reflexos neurológicos induzindo a resultados falsopositivos $^{27}$.

Três achados são cardinais para o diagnóstico de morte encefálica: a) coma aperceptivo, com ausência de respostas motoras supre espinais aos estímulos nociceptivos; b) ausência dos reflexos de tronco encefálico (pupilas médio-fixas ou em midríase paralítica; olhos de boneca e prova calóricas negativas; ausência de reflexos corneano, nauseoso ou de tosse) e c) presença de apneia, confirmada através do teste da apnéia ${ }^{5,6,27}$. A ordem no exame dos reflexos é opcional, com exceção do teste de apneia, que deve ser o último a ser pesquisado. A ausência dos reflexos integrados no tronco encefálico é fundamental no diagnóstico da morte encefálica ${ }^{5,6,27}$.

Todavia, no período neonatal e até os 12 meses de vida, em nosso país, conforme apontado anteriormente, o único exame confirmatório aceito é o eletroencefalograma (EEG).

O EEG deve obedecer às normas da Sociedade Americana de Eletroencefalografia ${ }^{5,6}$. Deverá ser observado o silêncio elétrico cerebral, que é definido como a ausência de atividade elétrica maior que dois micro $\mathrm{V}$, por um mínimo de 30 minutos.

Um fator que pode suscitar dúvida na interpretação do EEG é o uso de sedativos e anticonvulsivantes. Um exemplo de sedativo que causa significante interferência é fenobarbital, devido à sua meia vida prolongada. No período neonatal, níveis séricos de fenobarbital maiores que $25 \mathrm{mcg} /$ $\mathrm{dL}$ podem determinar silêncio elétrico cerebral ${ }^{7}$. A hipotermia também pode abolir a atividade metabólica e mimetizar a morte encefálica, porém alguns estudos têm mostrado que a supressão do EEG só ocorre em temperaturas inferiores a $29^{\circ} \mathrm{C}$, e que a perda completa da atividade elétrica cerebral só ocorre em temperaturas menores que $18^{\circ} \mathrm{C}$.

\section{Limitações diagnósticas no recém-nascido}

A determinação da morte encefálica no recémnascido baseia-se, sobretudo, na avaliação das funções do tronco encefálico. Porém, o diagnóstico apresenta algumas dificuldades no exame clínico, pois a avaliação das pupilas é prejudicada pela menor pigmentação da íris nesta faixa etária, e pelo frequente edema palpebral.

Adicionalmente, ocorre também constrição pupilar desencadeada por medicações utilizadas em pacientes graves. Nos prematuros, a dificuldade no reconhecimento de morte cerebral é ainda maior. Vários reflexos integrados no tronco encefálico, fundamentais na definição da morte encefálica, surgem apenas com 32-34 semanas de idade gestacional?.

Outro problema importante na definição diagnóstica de morte encefálica no paciente imaturo está relacionado ao estudo do fluxo sanguíneo cerebral (FSC). Os estudos de Ashwal ${ }^{7}$ mostraram que $1 / 3$ dos neonatos com diagnóstico confirmado de morte encefálica ainda apresenta FSC.

\section{Anencefalia e sua relação com transplante de ÓRGÃos: DILEMA BıOÉTICO}

Os temas éticos ocasionados pela anencefalia dizem respeito à vida e à dignidade humana, como salienta Barroso $^{9}$, entre o direito à vida do feto e a autonomia das mulheres. As discussões têm incidido sobre abortamento, em face do que se denomina 'antecipação terapêutica do parto'37.

A questão acerca do anencéfalo na condição de doador de órgãos apresenta pontos éticos difíceis e por vezes divergentes. Quanto à sua condição jurídica, se tomarmos como base o artigo 2o do Código Civil, Lei no 10.406 , de 10 de janeiro de 2002, a personalidade civil da pessoa começa do nascimento com vida, mas, a lei põe a salvo, desde a concepção, os direitos do nascituro. Sendo assim, criar um critério específico para o anencéfalo originaria uma zona de incerteza, na medida em que se individualizaria a ocorrência da morte em função de uma malformação. Por outro lado, a mudança dos critérios de morte, no caso da anencefalia, é motivada pela possibilidade deste ser empregado para o transplante de órgãos ${ }^{43}$.

Retomando o litígio de se alterar o conceito de morte encefálica para os casos de anencéfalos, primeiramente é importante ressaltar que "A Comissão Nacional de Bioética da Itália" não aceita o critério da morte neocortical. Tal conduta fundamenta-se no fato do paleoncéfalo permanecer íntegro, bem como a capacidade de regulação central homeostática do organismo e a capacidade de respiração autônoma ${ }^{19}$. Assim, também se põe em dúvida a aceitabilidade, no Brasil, da morte de seres que ainda estão respirando autonomamente, considerando-se principalmente que esta mudança acarretaria repercussão para os familiares daqueles que se encontram em estado vegetativo persistente 
ou demência profunda.

Outra questão que se coloca, além da mudança do critério de morte, é acerca da terapia que seria necessário instituir para a preservação da vida do anencéfalo. A respeito deste tema, Garrafa traz uma interrogação preocupante: quando a criança nascer, apesar do prazo mínimo de vida que terá, deverá ser mantida em tratamento permanente visando ao prolongamento máximo possível de sua vida? Deve-se estabelecer um limite para a terapia intensiva, eis que se trata de morte inevitável? ${ }^{30}$.

No entanto, existem posicionamentos divergentes quanto à conduta a ser empregada aos anencéfalos logo após seu nascimento. Para Casella ${ }^{18}$, por exemplo, deve ser efetuada somente terapia básica com nutrição, hidratação e remoção de secreções até ocorrer a morte encefálica. Kipper ${ }^{35}$, por sua vez, sugere que se deve oferecer suporte vital para o anencéfalo a fim de que sua condição, antes da morte encefálica, não se deteriore e impossibilite a doação de órgãos.

Segundo afirma, com a aprovação da Lei dos Transplantes (Lei ㄲo 9.434/97, art. 3ํ). Contudo, isto não significa que os demais tecidos e órgãos estejam mortos. A morte encefálica simplesmente atesta a total impossibilidade de sobrevida do indivíduo. Caso contrário, não seria permitido retirar, para transplante, um coração que ainda pulsa de um indivíduo com encéfalo ${ }^{10}$

No Parecer no 24/03 do CFM, emitido no Processo-Consulta $n^{\circ} 1.839 / 98$, considera-se que deva ser respeitado o desejo de uma mãe de levar a gestação ao termo ao invés de solicitar um aborto, com o quais muitos juízes já estão concordantes. Além do mais, o casal pode optar, após o nascimento, doar seus órgãos para salvar outras crianças com chances de vida (CFM, 2003).

O fato é que as crianças só podem receber órgãos de outras crianças com dimensões compatíveis, e os anencéfalos dispõem de órgãos viáveis para transplantes. O próprio CFM pronunciouse favorável à doação de órgãos e/ou tecidos de anencéfalos para transplante, após o Parecer supra citado, agora, por meio da Resolução $\mathrm{n}^{\circ} 1.752 / 04$, desde que formalmente autorizada pelos pais com a antecedência mínima de 15 dias da data provável do nascimento ${ }^{14}$.

Contudo, a resolução $\mathrm{n}^{\circ} 1.949$, de 10 de junho de 2010 revoga a Resolução CFM no 1.752/04, que trata da autorização ética do uso de órgãos e/ou tecidos de anencéfalos para transplante, mediante autorização prévia dos pais.

A primeira dificuldade para que se chegue a um consenso quanto à doação de órgãos de anencefálicos consiste na determinação inequívoca de sua morte. Admitindo-se que a vida do anencéfalo, de regra, não excede os sete dias requisitados para a segurança do diagnóstico de morte encefálica, os conhecimentos atuais não permitem estabelecer critérios válidos e verificáveis para determinar sua extinção apenas com exames clínico e laboratoriais ${ }^{3,8}$.

A outra dificuldade seria a manutenção da qualidade dos órgãos do anencéfalo até que sobrevenha sua morte e eles possam, enfim, ser removidos. Se o possível doador receber meramente os cuidados rotineiros, seus órgãos logo sofrerão deterioração irreversível por efeito de hipóxia, o que inviabilizará seu uso. Desse modo, seria necessário que a conservação da viabilidade visceral fosse feita mediante a submissão do anencéfalo a cuidados intensivos ${ }^{47}$

Contudo, as dificuldades relacionadas ao anencéfalo também podem ser consideradas para o neonato, uma vez que não há entendimento unívoco acerca da potencialidade do encéfalo do mesmo, pois, pode ser entendido como um órgão em formação com potencialidade variável ${ }^{19}$.

Assim, ao se considerar o número de crianças que aguardam um órgão para a sobrevivência, bem como a incompatibilidade vital que o anencéfalo apresenta, seria aceitável a retirada de órgãos do mesmo logo após sua expulsão do útero materno ${ }^{43}$.

Diante das dificuldades de se aplicar os critérios comumente utilizados para se aferir a morte cerebral em anencéfalos, seja em razão da sua idade de vida, seja em função de sua organização encefálica, sua condição de doador de órgãos revela-se extremamente afetada. Por outro lado, caso fosse empregado, no anencéfalo o critério da parada cardiorrespiratória, a doação se restringiria às válvulas cardíacas ${ }^{33}$.

\section{Anencefalia e Transplante de Órgãos: questões LEGAIS}

Os transplantes de órgãos e tecidos no Brasil estão normatizados pela Lei $n^{\circ} 9.434$, regulamentada pelo Decreto $n^{\circ}$ 2.268, ambos de 1997. Nesses textos jurídicos não há menção particular ao doador anencéfalo, todavia eles dispõem que o indivíduo incapaz, em vida, somente pode ser doador de medula óssea, ato que depende de prévia autorização de ambos os pais ou responsáveis legais e que deve ser reafirmado por autoridade judicial.

A Resolução CFM no 1.752 , de 08 de setembro de 2004, foi o primeiro documento brasileiro específico que visou a regulamentar a doação de órgãos de anencéfalos. Tal deliberação autorizava a remoção utilitarista de órgãos de anencéfalos, 
considerados "natimortos cerebrais", tão logo eles nascessem, desde que seus pais se manifestassem formalmente favoráveis no prazo máximo de 15 dias antes do parto ${ }^{47}$.

No entanto, houve a publicação, pelo Ministério da Saúde, da Portaria no 487, de 02 de março de 2007, a qual determina que a retirada de órgãos e/ou tecidos de neonato anencéfalo para fins de transplante ou tratamento deveria ser precedida de diagnóstico de parada cardíaca irreversível. Assim sendo, esta portaria traz uma determinação contrária a Resolução anteriormente mencionada ${ }^{47}$.

Observa-se que, conforme a Resolução CFM n 1.480/97, não há consenso sobre a aplicabilidade dos critérios dispostos naquele ato normativo em crianças menores de sete dias e prematuros. Entretanto, cabe ressaltar que o EEG e o FSC são compatíveis com os casos de anencefalia ${ }^{18}$.

Na Consulta n 8.905/98, do CREMESP, o Relator Consultor proferiu parecer no sentido de que sejam asseguradas as condições cardiorrespiratórias do anencéfalo para que seja viável o transplante, enfatizando que, cientificamente, não há perspectiva de vida para o mesmo ${ }^{43}$.

Assim sendo, a polêmica gira em torno dos aspectos éticos de uma lei que altere o critério de morte encefálica para o anencéfalo, considerando os aspectos incertos da Resolução CFM n 1.480/97, e venha a adotar o parâmetro da falência do neocórtex. Todavia, considerando o ordenamento jurídico brasileiro, uma lei federal pode alterar o parâmetro de morte para o caso do anencéfalo. A nenhum outro instrumento normativo cabe fazê-lo, nem mesmo qualquer ato regulador emitido pelo Conselho Federal de Medicina, como foi feito através da Resolução CFM no 1.752/0411. $\mathrm{Na}$ estrutura hierárquica do ordenamento brasileiro, as leis federais são superiores em relação a ato normativo oriundo do CFM. Portanto, de acordo com a Lei $n$ o 9.434/97, o critério de morte para qualquer pessoa é a morte encefálica ${ }^{43}$.

\section{DISCUSSÃO}

A anencefalia tem sido alvo de inúmeros debates, envolvendo questões médicas, éticas, legais e religiosas. Por ser um tema polêmico e controverso, a anencefalia atinge vários aspectos, como a gestação, com as alterações maternas, físicas e psíquicas; o feto, com o debate sobre o aborto eugênico ainda não previsto na legislação brasileira; e até a criança, com a possibilidade de doação de órgãos para transplantes.

Se, por um lado, há aqueles que defendem o direito dos pais terem esse filho, principalmente pelo apego a esse ser, mesmo conscientes de sua inviabilidade, por outro, há os que defendem a tese do aborto eugênico, tão logo seja constatada a malformação que vai inviabilizar a vida daquele ser.

Em face de argumentos diversos sobre 0 tema, parece existir uma contradição aparente nas noções de organismo vivo e pessoa morta.

Deve ser observado que, em relação aos prematuros e recém-nascidos de termo nos primeiros sete dias de vida, não existem critérios estabelecidos. Isto se deve à avaliação tanto clínica como dos exames subsidiários nesta faixa etária.

É notório que, para a retirada post mortem de órgãos, tecidos ou partes do corpo humano para fins de doação em adultos, conforme artigo 3o da Lei no. 9.434, de 04 de fevereiro de 1997, deve ocorrer primeiramente o diagnóstico de morte encefálica do paciente, mediante a utilização de parâmetros clínicos e tecnológicos definidos na resolução $\mathrm{n}$ 을. 1480/97 do Conselho Federal de Medicina (CFM). Somente então proceder-se-á ao explante dos órgãos.

Advém que não é possível aproveitar o mesmo dispositivo legal para o explante de órgãos de recémnascidos anencéfalos, devido à impossibilidade de diagnosticar-se a morte encefálica, considerando a própria ausência anatômica das estruturas que dão origem aos potenciais elétricos cerebrais.

A atual legislação impede a utilização do anencéfalo como doador, enquanto mantiver sinais de vida com respiração espontânea e choro, uma vez que são sinais de funcionamento de seu tronco cerebral e de não caracterização completa de morte encefálica.

Assim, nota-se que não se tem um consenso acerca do tratamento que deve ser empregado ao neonato anencéfalo, na medida em que sua morte é mera questão de tempo.

\section{CONCLUSÃO}

A constatação é que, enquanto se espera a satisfação dos critérios de morte do tronco cerebral, não se consegue obter órgãos que sejam viáveis para transplantes, mesmo com suporte de terapia intensiva, já que as repetidas apneias e bradicardias, típicas desses recém-nascidos, causam lesões hipóxicas e isquêmicas nos órgãos antes da morte, tornando limitada a doação de órgãos do anencéfalo.

Cientes de que toda problemática apontada não será facilmente solucionada, apenas tenta-se, a partir da dissertação, contribuir para o debate em torno de tal tópico. 
Carvalho FI, Miziara CSMG. Anencephalic children and organ donation: ethical and legal issues in Brazil. Saúde, Ética \& Justiça. 2012;17(1):3-11.

ABSTRACT: The present study has the objective analyze the medical, legal and ethical challenge imposed by the debate of use of organs from anencephalic neonates for transplantation from the point of view bioethics in Brazil. The path to achieve the goal was the method descriptive and exploratory; the literature search conducted from books, magazines, papers, journals. Anencephaly, is a severe defect of the embryonic central nervous system, has been the subject of heated debates in several sectors of Brazilian society and several questions can be brought up: i. Babies with anencephaly may be considered as persons? ii. Are they potential organ donors? iii. If so, under which circunstances? iv. Can the definition of death or brain death be changed? v. Is it should be practice intensive support of life for neonates with anencephaly? vi. How the priorities should be determined in neonatal units with limited resources? The present project has as main goal contribute to the debate about the anencephalic as organ donor, the legal and ethical issues surrounding the topic.

KEYWORDS: Anencephaly; Directed tissue donation/ethics; Bioethics; Tissue donors/ethics; Forensic medicine/ethics.

\section{REFERÊNCIAS}

1. Ahwal S, Peabody JL, Scheider S, Tomasi LG, Emergy JR, Peckam N. Anencephaly: clinical determination of brain death and neuropathologic studies. Pediatr Neurol. 1990;6:233-9.

2. Alberts B, Bray D, Johnson A, Lewis J, Raff M, Roberts K, Walter P. Molecular biology of the cell. 4th ed. 2002 [cited 2011 Nov 18]. Available from: http://www.ncbi.nlm.nih.gov/sites/ entre? $\mathrm{db}=$ books\&cmd=fertilization $\% 20$ AND $\% 20$ mboc4\%5Bbook\%5D\&doptcmdl=TOCView . Search\&term

3. American Academy of Pediatrics Task Force on Brain Death in Children. Guidelines for the determination of brain death in children. Pediatrics. 1987;80:298-300.

4. Antonsson P, Sundberg A, Kublickas M, Pilo C, Ghazi S, Westgren M, Papadogiannakis N. Correlation between ultrasound and autopsy findings after 2 nd trimester terminations of pregnancy. J Perinat Med. 2008;36:59-69.

5. Ashwal S, Schneider S. Brain death in children. Part I. Pediatr Neurol. 1987;3:5-11.

6. Ashwal S, Schneider S. Brain death in children. Part II. Pediatr Neurol. 1987;3:69-77.

7. Ashwal S. Brain death in the newborn. Clin Perinatol. 1997;24:859-82.

8. Banasiak KJ, Lister G. Brain death in children. Curr Opin Pediatr. 2003;15:288-93.

9. Barroso LR. Gestação de fetos anencefálicos e pesquisas com células-tronco: dois temas acerca da vida e da dignidade na Constituição. Panóptica. 2007;1:1-37 [citado em 2 nov. 2011]. Disponível em: http://www.panoptica.org/marco_abril07pdf/ ano1_n\%5B15

10. Becker MA. Pareceres e resoluções. Bioética. 2004;12(2):145 [citado em 4 out. 2011]. Disponível em: http://www.portalmedico.org.br/bioetica/index. php?selecionaRevista $=24 \&$ opcao $=$ revista\#.

11. Bobbio N. Teoria do ordenamento jurídico. 9a ed. Brasília: UnB; 1997.

12. Brasil. Leis e decretos. Critérios para a caracterização da morte encefálica. Resolução $\mathrm{n}^{\circ}$ 1.480 do Conselho Federal de Medicina do Brasil. Diário Oficial da União, 08 ago. 1997.

13. Brasil. Lleis e decretos. Disposições sobre a retirada e transplante de tecidos, órgãos e partes do corpo humano, com fins terapêuticos, científicos e humanitários. Lei oㅜ 4.934 da República Federativa do Brasil. Diário Oficial da União, 04 fev. 1997.

14. Brasil. Conselho Federal de Medicina. Resolução no. 1.752, de 08 de setembro de 2004. Dispõe sobre a autorização ética do uso de órgãos e/ou tecidos de anencéfalos para transplante, mediante autorização prévia dos pais. Diário Oficial da União. Brasília, 13 set. 2004. p. 140.

15. Brasil. Decreto no 2.268, de 30 de junho de 1997. Regulamenta a Lei no 9.434, de 04 de fevereiro de 1997, que dispõe sobre a remoção de órgãos, tecidos e partes do corpo humano para fim de transplante e tratamento, e dá outras providências. Diário Oficial da União, Brasília, DF, 01 jul. 1997. p. 13.739.

16. Brasil. Lei no 9.434, de 04 de fevereiro de 1997. Dispõe sobre a remoção de órgãos, tecidos e partes do corpo humano para fins de transplante e tratamento e dá outras providências. Diário Oficial da União, Brasília, DF, 05 fev. 1997. p. 2.191.

17. Canick JA, Kellner LH, Bombard AT. Prenatal screening for open neural tube defects. Clin Lab Med. 2003;23:385-94.

18. Casella EB. Morte encefálica e neonatos como doadores de órgãos. Pedriatria (São Paulo). 2003;25:184-90. 
19. Comitato Nazionale Per La Bioetica. I neonato anecefalico e la donazione di organi [citado em 24 out. 2011]. Disponível, em: http://www.aido.it/ trapianto-bioetica.

20. Conselho Federal de Medicina. Parecer CFM no 24/03. Aprovado em 9 de maio de 2003. [acesso em 4 jun 2009]. Uso de órgãos de anencéfalos para transplante. Ente com incompatibilidade vital por não possuir a parte nobre e vital do cérebro. Uma vez autorizado formalmente pelos pais, o médico poderá proceder ao transplante de órgãos do anencéfalo após a sua expulsão ou retirada do útero materno. Relator de vistas: Marco Antonio Becker. Disponível em: http://www.portalmedico. org.br/pareceres/cfm/2003/24_2003.htm.

21. Conselho Federal de Medicina. Resolução CFM $\mathrm{n}^{\circ}$ 1.752, de 8 de setembro de 2004. Autorização ética do uso de órgãos e/ou tecidos de anencéfalos para transplante, mediante autorização prévia dos pais [citado em 4 out 2011]. Disponível em: http://www.portalmedico.org.br/resolucoes/ cfm/2004/1752_2004.htm.

22. Conselho Regional DE Medicina do Estado de São Paulo. Consulta no 8.905. Solicita parecer sobre caso de gestação na qual foi constatado anencefalia fetal e sobre a dúvida em interromper a gravidez ou dar continuidade e doar os órgãos. Parecerista: Marco Segre. Aprovado na $2.071^{a}$ Reunião Plenária, 10 fev. 1998.

23. Cook RJ, Erdman JN, Hevia M, Dickens BM. Prenatal management of anencephaly. Int J Gynaecol Obstet. 2008;102:304-8.

24. Cost, A. Introdução ao direito: uma perspectiva ética das ciências jurídicas. Porto Alegre: Sergio Fabris; 2001.

25. Diniz D. Aborto e inviabilidad fetal: el debate brasileño. Cad Saúde Pública. 2005;21:634-9.

26. Diniz D. Selective abortion in Brazil: the anencephaly case. Dev World Bioeth. 2007;7:64-7.

27. Dobb GJ, Weekes JW. Clinical confirmation of brain death. Anaesth Intens Care. 1995;23:37-43.

28. Febrasco. Federação Brasileira das Associações de Ginecologia e Obstetrícia. Disponível em: http:// www.febrasgo.org.br.

29. França GV. Direito médico. In: França GV, editor. Transplantes de órgãos e tecidos. 8a ed. São Paulo: BYK; 2003. p. 377-407. Brasil. Conselho Federal de Medicina. Resolução no. 1.480 , de 08 de agosto de 1997. Dispõe sobre os critérios para confirmação de morte. Diário Oficial da União, Brasília, DF, 21 ago. 1997. p. 18.227.

30. Garrafa V. Caso clínico [citado em 26 set. 2011]. Disponível, em: http://www.crmma.cfm.org.br.

31. Harding B, COPP AJ. Pathology of malformations. In: Graham DI, Lantos PL, editors. Greenfield's neuropathology. 6th ed. New York: Oxford University Press; 1997. p.412-3.
32. Harvard Medical School. A definition of irreversible coma: report of the Ad Hoc Committee of the Harvard Medical School to Examine the Definition of Brain Death. JAMA, 1968;205:337-40.

33. Instituto Nacional Central Único Coordinador de Ablación e Implante. Anencefalia e donación de órganos [citado em 24 out. 2011]. Disponível, em: http://www.incucai.gov.ar.

34. Kalucy M, Bower C, Stanley F, Burton P. Survival of infants with neural tube defects in Western Australia 1966-1990. Paediatr Perinat Epidemiol. 1994;8:33451.

35. Kipper, D. Caso clínico [citado 26 set. 2011]. Disponível em: http://www.crmma.cfm.org.br.

36. Martínez VMR, Ruiz CL, Lombada RS, Bermúdez LC, Peña LR, Rodriguez AN, Penco JMP, Arce RC, Castillo D, Ramiro JC, Rodriguez JO. Comparación entre el diagnóstico prenatal y anatomopatológico de las anomalias congénitas. Rev Cubana Obstet Ginecol. 2007;33:1-10.

37. Massud M. Anencefalia numa perspectiva ética. Rev Bras Saúde Matern Infant (Recife). 2010;10(Supl. 2):S263-S70.

38. Mcabee G, Sherman J, Canas JA, Boxer H. Prolonged survival of two anencephalic infants. Am J Perinatol. 1993;10:175-7.

39. Moisés ECD, Cunha SP, Duarte LB, Miziara FC, Carvalho RC, Berezowski AT, Duarte G. Aspectos éticos e legais do aborto no Brasil. Ribeirão Preto: Funpec-Editora; 2005. p. 20.

40. Moore KL, Persuad TVN. Embriologia clinica. 6 ed. Rio de Janeiro: Editora Guanabara; 2000.

41. Moreira, N. Caso clínico [citado 26 out. 2011]. Disponível em: http://www.crmma.cfm.org.br.

42. Norem CT, Schoen EJ, Walton DL, Krieger RC, O'keefe, TT, Ray GT. Routine ultrasonography compared with maternal serum alpha-fetoprotein for neural tube defect screening. Obstet Gynecol. 2005;106:747-52.

43. Oliveira AAS. Anencefalia e transplante de órgãos. Rev Soc Bras Bioética. 2005.

44. Pazo JH, editor. Fisiologia do sistema somatosensorial. In: Cingolani HE, Houssay AB. Fisiologia humana de Houssay. Trad. Adriene Belló Klein et al. 7a ed. Porto Alegre: Artmed; 2004. p.811-40.

45. President's Commission for the Study of Ethical Problems in Medicine and Biomedical and Behavioral Research. Guidelines for the determination of death. JAMA. 1981; 246:2184-7.

46. Resolution on Physicians Conduct Concerning Human Organ Transplantation. 46th General Assembly. Stockholm; 1994.

47. Rocha, RF. O anencéfalo como doador de órgãos e tecidos para transplante: possibilidades legais, morais e práticas. Rev Bras Saúde Matern Infant 
Carvalho FI, Miziara CSMG. Crianças anencefálicas e doações de órgãos: questões legais e éticas no Brasil.

(Recife). 2010;10 (Supl. 2):S297-S302.

48. Ruiz R, Cuneo MF, Lacuara JL, editors. Fertilização. In: Cingolani HE, Houssay AB. Fisiologia humana de Houssay. Trad. Adriene Belló Klein et al. 7a ed. Porto Alegre: Artmed; 2004. p.718-9.

49. Segre M. Caso clínico [citado em 26 set. 2011]. Disponível em: http://www.crmma.cfm.org.br.

50. Statement on Human Organ Donations and Transplantation. 52nd General Assembly. Edinburgh, oct. 2000. Revised by the General Assembly. Pilanesberg; 2006.

51. Stool C, Alembik Y, Dott B. Associated malformations in cases with neural tube defects. Genet Couns. 2007;18:209-15.
52. Task Force for the Determination of Brain Death in Children. Guidelines for the determination of brain death in children. Arch Neurol. 1987;44:587-8.

53. Wald M, Lawrenz K, Deutinger J, Weninger M. Verification of anomalies of the central nervous system detected by prenatal ultrasound. Ultraschall Med. 2004;25:214-7.

54. Walsh JL, Mcqueen MM. The morality of induced delivery of the anencephalic fetus prior to viability. Kennedy Inst Ethics J. 1993;3:357-69.

55. World Medical Association. Declaration on human organ transplantation. In: 39th World Medical Assembly. Madrid; 1987. 